University of Nebraska - Lincoln

DigitalCommons@University of Nebraska - Lincoln

2020

Measuring Research Productivity and Performance of Medical Scientists on Coronary Artery Disease in Brazil: A Metric Study

Muneer Ahmad

muneerbangroo@gmail.com

Dr. M.Sadik Batcha

Annamalai University

Follow this and additional works at: https://digitalcommons.unl.edu/libphilprac

Part of the Scholarly Communication Commons

Ahmad, Muneer and Batcha, Dr. M.Sadik, "Measuring Research Productivity and Performance of Medical Scientists on Coronary Artery Disease in Brazil: A Metric Study" (2020). Library Philosophy and Practice (e-journal). 4358.

https://digitalcommons.unl.edu/libphilprac/4358 


\title{
Measuring Research Productivity and Performance of Medical Scientists on Coronary Artery Disease in Brazil: A Metric Study
}

\author{
Muneer Ahmad $^{1}$ Dr. M Sadik Batcha ${ }^{2}$
}

${ }^{1}$ Research Scholar, Department of Library and Information Science, Annamalai University, Annamalai nagar, muneerbangroo@gmail.com

${ }^{2}$ Research Supervisor \& Mentor, Professor and University Librarian, Annamalai University, Annamalainagar,msbau@ rediffmail.com

\begin{abstract}
The aim of this study was to analyze Brazil research performance on Coronary Artery Disease as reflected in indexed publications in Web of Science with a view to understand their distribution of research output, top journals for publications, most prolific authors, authorship pattern, and citations pattern on CAD. The results indicate that highest growth rate of publications occurred between the years 1995-1999. University Sao Paulo topped the scene among all institutes. The maximum publications were more than ten authored publications. Ramires JAF and Santos RD were found to be the most prolific authors. It is also found that most of the prolific authors (by number of publications) do not emerge in highly cited publications' list. CAD researchers mostly preferred using article publications to communicate their findings.
\end{abstract}

Keywords: Coronary Artery Disease, Bibliometrix Package, RStudio, Literature Growth, $\mathrm{h}$ index, $g$ index, $m$ index.

\section{Introduction}

Coronary artery disease (CAD) refers to the build-up of atherosclerotic plaque in the blood vessels that supply oxygen and nutrients to the heart (Braunwald \& Bonow, 2012). The complex process of atherosclerosis begins early in life and is thought to initiate with dysfunction of endothelial cells that line the coronary arteries; these cells are no longer able to appropriately regulate vascular tone (narrowing or constriction of the vessels) with nitric oxide signaling. Progressive infiltration of the vessel wall by lipoprotein particles carrying cholesterol propagates an inflammatory response by cholesterol-loaded macrophage 'foam cells'. Smooth muscle cells underlying the vessel wall proliferate and lead to remodeling of the vessel that can ultimately lead to a narrowing of the vessel that obstructs blood flow. A myocardial infarction (heart attack) is typically caused when a blood clot is incited by a rupture in the surface of the plaque; this 
process deprives the heart muscle downstream of the blood clot of adequate blood flow and leads to cell death (Khera \& Kathiresan, 2017).

The prevalence of CAD, also known as coronary heart disease (CHD), has been observed to vary greatly according to the geographical locations, ethnicity, and gender (Go et al., 2014). Epidemiological studies on such cardiovascular diseases have provided information which could guide the strategies of prevention and eradication of these diseases both at the individual and population levels (Wong, 2014). Even before the field of cardiovascular epidemiology existed, in Minnesota (United States) the first prospective studies of CAD prevalence in population was conducted in 1946 (Keys et al., 1963). In the seven countries study, the relationships between lifestyle, diet, CAD, and stroke were elucidated (Keys, 1980). This study also indicated that the rates of heart attack and stroke were directly related to the levels of total cholesterol and this remained constant across different countries and cultures (Epstein, Blackburn, \& Gutzwiller, 1996).

\section{Review of Literature}

Numerous studies have been conducted in the areas of Scientometrics, Bibliometrics and related to it, Webometrics (Ahmad, Batcha, Rashid, \& Hafiz, 2018). The discipline has been widely spread through different journals, conference articles, monographs, textbooks, etc, especially in the recent decades. In view of the huge amount of literature available in the field, an attempt has been made to review only significant and recent literature on the various aspects of scientometrics research. (Batcha \& Ahmad, 2017) obtained the analysis of two journals Indian Journal of Information Sources and Services (IJSS) which is of Indian origin and Pakistan Journal of Library and Information Science (PJLIS) from Pakistan origin and studied them comparatively with scientometric indicators like year wise distribution of articles, pattern of authorship and productivity, degree of collaboration, pattern of co-authorship, average length of papers, average keywords. The collaboration with foreign authors of both the countries is negligible (1.37\% of articles) from India and (4.10\% of articles) from Pakistan.

(Ahmad, Batcha, Wani, Khan, \& Jahina, 2018) studied Webology journal one of the reputed journals from Iran was explored through scientometric analysis. The study aims to provide a comprehensive analysis regarding the journal like year wise growth of research articles, authorship pattern, author productivity, and subjects taken by the authors over the period of 5 years from 2013 to 2017 . The findings indicate that 62 papers were published in the journal 
during the study period. The articles having collaborative nature were high in number. Regarding the subject concentration of papers of the journal, Social Networking, Web 2.0, Library 2.0 and Scientometrics or Bibliometrics were highly noted.

(Batcha, Jahina, \& Ahmad, 2018) has examined the DESIDOC Journal by means of various scientometric indicators like year wise growth of research papers, authorship pattern, subjects and themes of the articles over the period of five years from 2013 to 2017 . The study reveals that 227 articles were published over the five years from 2013 to 2017. The authorship pattern was highly collaborative in nature. The maximum numbers of articles (65\%) have ranged their thought contents between 6 and 10 pages.

(Ahmad \& Batcha, 2019) analyzed research productivity in Journal of Documentation (JDoc) for a period of 30 years between 1989 and 2018. Web of Science a service from Clarivate Analytics has been consulted to obtain bibliographical data and it has been analysed through Bibexcel and Histcite tools to present the datasets. Analysis part deals with local and global citation level impact, highly prolific authors and their research output, ranking of prominent institution and countries. In addition to this scientographical mapping of bibliographical data is obtainable through VOSviewer, which is open source mapping software.

(Ahmad \& Batcha, in 2019) studied the scholarly communication of Bharathiar University which is one of the vibrant universities in Tamil Nadu. The study find out the impact of research produced, year-wise research output, citation impact at local and global level, prominent authors and their total output, top journals of publications, top collaborating countries which collaborate with the university authors, highly industrious departments and trends in publication of the university during 2009 through 2018. In addition the study used scientographical mapping of data and presented it through graphs using VOSviewer software mapping technique.

(Ahmad, Batcha, \& Jahina, 2019) quantitatively measured the research productivity in the area of artificial intelligence at global level over the study period of ten years (2008-2017). The study acknowledged the trends and features of growth and collaboration pattern of artificial intelligence research output. Average growth rate of artificial intelligence per year increases at the rate of 0.862 . The multi-authorship pattern in the study is found high and the average number of authors per paper is 3.31. Collaborative Index is noted to be the highest range in the year 2014 with 3.50. Mean CI during the period of study is 3.24. This is also supported by the mean degree of collaboration at the percentage of 0.83 .The mean CC observed is 0.4635 . Regarding the 
application of Lotka's Law of authorship productivity in the artificial intelligence literature it proved to be fit for the study.

(Batcha, Dar, \& Ahmad, 2019) presented a scientometric analysis of the journal titled "Cognition" for a period of 20 years from 1999 to 2018. The present study was conducted with an aim to provide a summary of research activity in current journal and characterize its most aspects. The research coverage includes the year wise distribution of articles, authors, institutions, countries and citation analysis of the journal. The analysis showed that 2870 papers were published in journal of Cognition from 1999 to 2018. The study identified top 20 prolific authors, institutions and countries of the journal. Researchers from USA have made the most percentage of contributions.

(Batcha, Dar, \& Ahmad, 2020) conducts a scientometric study of the Modern Language Journal literature from 1999 to 2018 . A total of 2564 items resulted from the publication name using "Modern Language Journal" as the search term was retrieved from the Web of Science Database. Based on the number of publications during the study period, no consistent growth was observed in the research activities pertaining to the journal. The annual distribution of publications, number of authors, institution productivity, country wise publications and Citations are analyzed. Highly productive authors, institutions, and countries are identified. The results reveal that the maximum number of papers 179 is published in the year 1999. It was also observed that Byrnes $\mathrm{H}$ is the most productive, contributed 51 publications and Kramsch $\mathrm{C}$ is most cited author in the field having 543 global citations. The highest number (38.26\%) of publications, contributed from USA and the foremost productive establishment was University of Iowa.

(Ahmad, Batcha, \& Dar, 2020) studied the Brain and Language journal which is an interdisciplinary journal, publishes articles that explicate the complex relationships among language, brain, and behavior and is one such journal which is concerned with investigating the neural correlates of Language. The study aims at mapping the structure of the Brain and Language journal. The journal looks into the intrinsic relationship between language and brain. The study demonstrates and elaborates on the various aspects of the Journal, such as its chronology wise total papers, most productive authors, citations, average citation per paper, institution and country wise distribution of publications for a period of 20 years.

(Ahmad \& Batcha, 2020) explores and analyses the trend of world literature on "Coronavirus Disease" in terms of the output of research publications as indexed in the Science Citation Index 
Expanded (SCI-E) of Web of Science during the period from 2011 to 2020. The study found that 6071 research records have been published on Coronavirus Disease. The various scientometric components of the research records published in the study period were studied. The study reveals the various aspects of Coronavirus Disease literature such as year wise distribution, relative growth rate, doubling time of literature, geographical wise, organization wise, language wise, form wise, most prolific authors, and source wise.

(Ahmad \& Batcha, 2020) analyzed the application of Lotka's law to the research publication, in the field of Dyslexia disease. The data related to Dyslexia were extracted from web of science database, which is a scientific, citation and indexing service, maintained by Clarivate Analytics. A total of 5182 research publications were published by the researchers, in the field of Dyslexia. The study found out that, the Lotka's inverse square law is not fit for this data. The study also analyzed the authorship pattern, Collaborative Index (CI), Degree of Collaboration (DC), Coauthorship Index (CAI), Collaborative Co-efficient (CC), Modified Collaborative Co-efficient (MCC), Lotka's Exponent value, Kolmogorov-Smirnov Test (K-S Test), Relative Growth Rate and Doubling Time.

(Umar, Ahmad, \& Batcha, 2020) studied and focused on the growth and development of Library and Culture research in forms of publications reflected in Web of Science database, during the span of 2010-2019. A total 890 publications were found and the highest 124 (13.93\%) publications published in 2019.The analysis maps comprehensively the parameters of total output, growth of output, authorship, institution wise and country-level collaboration patterns, major contributors (individuals, top publication sources, institutions, and countries).

(Ahmad \& Batcha, 2020) studied and examined 4698 Indian Coronary Artery Disease research publications, as indexed in Web of Science database during 1990-2019, with a view to understand their growth rate, global share, citation impact, international collaborative papers, distribution of publications by broad subjects, productivity and citation profile of top organizations and authors, and preferred media of communication.

(Jahina, Batcha, \& Ahmad, 2020) study deals a scientometric analysis of 8486 bibliometric publications retrieved from the Web of Science database during the period 2008 to 2017. Data is collected and analyzed using Bibexcel software. The study focuses on various aspect of the quantitative research such as growth of papers (year wise), Collaborative Index (CI), Degree of Collaboration (DC), Co-authorship Index (CAI), Collaborative Co-efficient (CC), Modified 
Collaborative Co-Efficient (MCC), Lotka's Exponent value, Kolmogorov-Smirnov test (K-S Test).

\section{Objectives}

The main objective of the present study is to study the growth of research output in Coronary Artery Disease from Brazil. Moreover, the study has been performed:

- To find out the type of documents containing Coronary Artery Disease research output in Brazil during 1990-2019;

- To analyse the year wise distribution and growth of literature on Coronary Artery Disease in Brazil during 1990-2019;

- To identify the top institutions conducting research on Coronary Artery Disease;

- To identify the most prolific authors conducting research on Coronary Artery Disease;

- To study the authorship pattern in Coronary Artery Disease research;

- To study the top sources preferred by authors for publishing Coronary Artery Disease research.

\section{Methodology}

The present study is a scientometric analysis of Coronary Artery Disease research publications. A total of 6211 records have been extracted from the Web of Science database in the '.txt' format covering the period (1990-2019). The search string used for data extraction is:

"TS=(Artery Disease, Coronary OR Artery Diseases, Coronary OR Coronary Artery Diseases OR Disease, Coronary Artery OR Diseases, Coronary Artery OR Coronary Arteriosclerosis OR Arterioscleroses, Coronary OR Coronary Arterioscleroses OR Atherosclerosis, Coronary OR Atheroscleroses, Coronary OR Coronary Atheroscleroses OR Coronary Atherosclerosis OR Arteriosclerosis, Coronary OR Ischaemic OR Ischemic OR hardening of the Arteries OR Induration of the Arteries OR Arterial Sclerosis ) AND CU=(Brazil)"

This search has been refined to limit the period from 1990 to 2019. Data filtering has been performed manually to remove irrelevant record entries. Bibliometrix Package in RStudio has been used for analyzing the data and it has also been used for tabulation and visualization of Results.

Calculations and statistical techniques were applied in the excel sheet to draw specific results. Total Publications (TP), Total Citations (TC), Average Citations per Paper (ACPP) h-index, g- 
index and m-index was calculated during analysis. ACPP is calculated by dividing the total citations received by the number of papers. The h-index was suggested by Jorge H. Hirch in 2005 (Hirsch, 2010). A scientist/ journal/ institution has index $\mathrm{h}$ if its $\mathrm{h}$ papers have atleast $\mathrm{h}$ citations each. Egghe defines g-index as "the highest rank such that the top g papers have, together, at least $\mathrm{g} 2$ citations. This also means that the top $\mathrm{g}+1$ have less than $(\mathrm{g}+1) 2$ papers". The g-index is always higher or equal to h-index, as has been also stated by (Egghe, 2006). mindex is another variant of the h-index that displays h-index per year since first publication. The h-index tends to increase with career length, and m-index can be used in situations where this is a shortcoming, such as comparing researchers within a field but with very different career lengths. The m-index inherently assumes unbroken research activity since the first publication

\section{Data Analysis and Findings}

\subsection{Type of Publications}

Different kind of publications in which research work on Coronary Artery Disease from Brazil is contributed during last 30 years is listed in Table 1. Out of total publications $4668(75.16 \%)$ are research articles, $565(9.10 \%)$ are meeting abstracts, $527(8.48 \%)$ are reviews, $157(2.53 \%)$ are editorial material, $136(2.19 \%)$ are article; proceedings paper, $117(1.88 \%)$ are letter, $13(0.21$ $\%)$ are article; early access, $6(0.10 \%)$ are article; book chapter, $6(0.10 \%)$ is note, $6(0.10 \%)$ are review \& book chapter, $4(0.06 \%)$ are correction, $3(0.05 \%)$ are new item and $1(0.02 \%)$ are article; retracted publication, editorial material; early access, and review; retracted publication . It is apparent that more research output was produced in the form of articles and is having highest ACPP (30.49) than other forms of publications. It is also evident that in spite of more research output was produced in articles but ACPP of research output published as reviews and article; proceedings paper was also fair amount (64.20) compared to articles (30.49). ACPP of review; book chapter having (25.17), note (13.50), editorial Material (9.41), letter (4.04). Article; retracted publication published on CAD also received 3.00 ACPP. Other type of documents had ACPP less than 3. Thus; it was observed that articles, reviews and article; proceedings paper received more citations than other forms of documents.

Table 1: Publication Type

\begin{tabular}{clcccc}
\hline S.No. & \multicolumn{1}{c}{ Document Type } & Publications & \% & TC & ACPP \\
\hline 1 & Article & 4668 & 75.16 & 142311 & 30.49 \\
2 & Meeting Abstract & 565 & 9.10 & 81 & 0.14
\end{tabular}




\begin{tabular}{clcccc}
3 & Review & 527 & 8.48 & 16363 & 31.05 \\
4 & Editorial Material & 157 & 2.53 & 1477 & 9.41 \\
5 & Article; Proceedings Paper & 136 & 2.19 & 4508 & 33.15 \\
6 & Letter & 117 & 1.88 & 473 & 4.04 \\
7 & Article; Early Access & 13 & 0.21 & 9 & 0.69 \\
8 & Article; Book Chapter & 6 & 0.10 & 17 & 2.83 \\
9 & Note & 6 & 0.10 & 81 & 13.50 \\
10 & Review; Book Chapter & 6 & 0.10 & 151 & 25.17 \\
11 & Correction & 4 & 0.06 & 2 & 0.50 \\
12 & News Item & 3 & 0.05 & 3 & 1.00 \\
13 & Article; Retracted Publication & 1 & 0.02 & 3 & 3.00 \\
14 & Editorial Material; Early & 1 & 0.02 & 0 & 0.00 \\
& Access & & & & \\
15 & Review; Retracted Publication & 1 & 0.02 & 17 & 17.00 \\
\hline \multicolumn{2}{r}{ TC "Total Citations", ACPP= “Average Citations per Paper" }
\end{tabular}

\subsection{Distribution of Research Publications}

There has been a continuous increase in publications from the first decade (1990-1999) to the latest decade (2010-2019). During last 30 years, about 68 per centre research output on CAD was contributed in decade third (2010-2019). Table 2 shows the distribution of research output in five blocks of five years each. It is very apparent that highest growth rate occurs in the block year 1995-1999 (70.40 \%) followed by 2005-2009 (62.26\%). Almost one-third (35.36 \%) research output on CAD was contributed during 2010-2014. In first block year, research output was $(1.06 \%)$ and in second block it increased (3.59\%) and in third block it again increased (7.63\%) and afterwards increased continuously by every block year. Highest number of research was contributed in the block 2015-2019 (30.21\%).

Table 2 : Distribution of Papers during 1990-2019

\begin{tabular}{ccccc}
\hline Year & Articles & \% of TP & CO & \% of Growth \\
\hline $1990-1994$ & 66 & 1.06 & 66 & -- \\
$1995-1999$ & 223 & 3.59 & 289 & 70.40 \\
$2000-2004$ & 474 & 7.63 & 763 & 52.95 \\
$2005-2009$ & 1256 & 20.22 & 2019 & 62.26 \\
$2010-2014$ & 1943 & 31.28 & 3962 & 35.36 \\
$2015-2019$ & 2249 & 36.21 & 6211 & 13.61 \\
\hline Total & 6211 & 100.00 & & \\
\hline
\end{tabular}

$\mathrm{TP}=$ "Total Publications", $\mathrm{CO}=$ "Cumulative Output", Formula of Growth= "Final Value-Start Value/Start Value X100" 


\subsection{Institution-wise Research Share}

The top 20 institutions that produced highest research outputs on CAD during the period under study are listed in Table 3 . Table 3 summarizes total articles, the total citation score, and average citation per paper of the publications of these institutions. In total, 11033 institutions, including 20765 subdivisions published 6211 research papers during 1990 - 2019. The topmost twenty institutions involved in this research have published 83 and more research articles. The mean average is 0.56 research articles per Institution. Out of 11033 institutions, top 20 institutions published 8020 collaboratively research papers. It is also observed that among twenty top Institutions which contributed highest research output on CAD, University Sao Paulo took the lead by producing research output of 2211 publications followed by University Fed Sao Paulo with 502 research publications followed by University Fed Rio Grande do Sul with 402 research publications followed by University Fed Minas Gerais with 303 research publications. Eleven institutions produced 100 or more than 100 research publications on CAD. In terms of citations, University Sao Paulo received highest citations i.e. 66817 for 2211 total research publications. It is also noticed that Harvard University, had highest ACPP (194.74).

Table 3: Top Institutions Research Output

\begin{tabular}{clcccc}
\hline S.No. & \multicolumn{1}{c}{ Institution } & Publications & \% & TC & ACPP \\
\hline 1 & University Sao Paulo & 2211 & 39.47 & 66817 & 30.22 \\
2 & University Fed Sao Paulo & 502 & 8.96 & 27489 & 54.76 \\
3 & University Fed Rio Grande do Sul & 402 & 7.18 & 15158 & 37.71 \\
4 & University Fed Minas Gerais & 303 & 5.41 & 11352 & 37.47 \\
5 & University Fed Rio de Janeiro & 280 & 5.00 & 6105 & 21.80 \\
6 & University Estadual Campinas & 225 & 4.02 & 4694 & 20.86 \\
7 & Inst Dante Pazzanese Cardiol & 176 & 3.14 & 12231 & 69.49 \\
8 & Hospital Clin Porto Alegre & 152 & 2.71 & 7011 & 46.13 \\
9 & Hospital Israelita Albert Einstein & 150 & 2.68 & 1904 & 12.69 \\
10 & Harvard University & 137 & 2.45 & 26680 & 194.74 \\
11 & Brigham \& Womens Hospital & 135 & 2.41 & 13704 & 101.51 \\
12 & Johns Hopkins University & 125 & 2.23 & 18350 & 146.80 \\
13 & University Fed Fluminense & 117 & 2.09 & 1476 & 12.62 \\
14 & University Toronto & 110 & 1.96 & 12589 & 114.45 \\
15 & University Estado Rio De Janeiro & 107 & 1.91 & 1736 & 16.22 \\
16 & University Fed Parana & 99 & 1.77 & 910 & 9.19 \\
17 & Harvard Medical School & 97 & 1.73 & 8235 & 84.90 \\
18 & Columbia University & 96 & 1.71 & 17383 & 181.07 \\
19 & Duke University & 95 & 1.70 & 16103 & 169.51
\end{tabular}




\section{Most Relevant Affiliations}

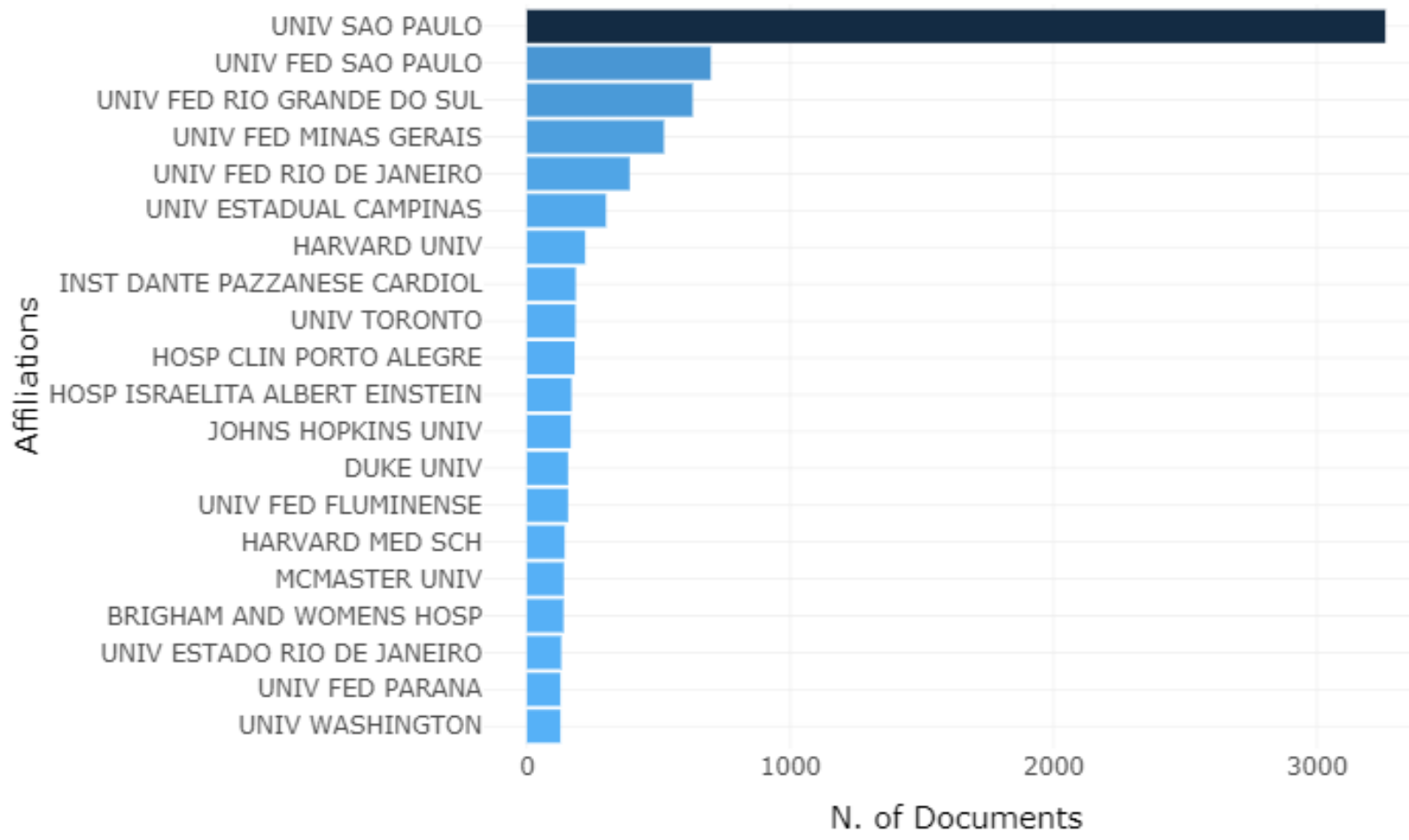

\subsection{Most Prolific Authors}

The list of twenty top authors who produced highest contribution to research output on CAD in Brazil is given in Table 4. In terms of number of publications, Ramires JAF is the most productive author with 231 publications followed by Santos RD 146, Hueb W 137, and Kalil R 117 publications. It is also noted that 5 out of 20 prolific authors contributed more than hundred research publications each while rest 15 authors contributed more than 60 publications each. The ACPP on research output contributed by Serruys PW (101.89) was recorded highest that was distantly followed by Lotufo PA (94.63). The h index is highest for Santos RD (32) followed by Ramires JAF (29) followed by Serruys PW (28) and Rochitte CE, Nicolau JC \& Abizaid A (25). The data set puts forth that the authors Lotufo PA with $90 \mathrm{~g}$ index, Nicolau JC with $77 \mathrm{~g}$ index, Santos RD with $75 \mathrm{~g}$ index, Bensenor IM with $74 \mathrm{~g}$ index and Serruys PW with $73 \mathrm{~g}$ index. Rochitte CE (1.39), Abizaid A (1.25), Bittencourt MS (1.15) are having the highest $m$ index respectively. 
Table 4: Most Prolific Authors

\begin{tabular}{lcccccc}
\hline \multicolumn{1}{c}{ Author } & NP & TC & ACPP & h-index & g-index & m-index \\
\hline Ramires JAF & 231 & 3750 & 16.23 & 29 & 55 & 0.92 \\
Santos RD & 146 & 5804 & 39.75 & 32 & 75 & 0.57 \\
Hueb W & 137 & 3025 & 22.08 & 22 & 54 & 0.81 \\
Kalil R & 117 & 1008 & 8.62 & 15 & 30 & 0.87 \\
Pereira AC & 110 & 1324 & 12.04 & 19 & 31 & 0.95 \\
Rochitte CE & 99 & 3412 & 34.46 & 25 & 57 & 1.39 \\
Cesar LAM & 96 & 1121 & 11.68 & 17 & 31 & 0.57 \\
Nicolau JC & 94 & 5990 & 63.72 & 25 & 77 & 0.93 \\
Abizaid A & 88 & 2764 & 31.41 & 25 & 51 & 1.25 \\
Maranhao RC & 93 & 1234 & 13.27 & 21 & 30 & 0.56 \\
Lotufo PA & 90 & 8517 & 94.63 & 23 & 90 & 0.88 \\
Bittencourt MS & 78 & 1084 & 13.90 & 15 & 31 & 1.15 \\
Krieger JE & 77 & 974 & 12.65 & 17 & 27 & 0.85 \\
Bensenor IM & 74 & 6881 & 92.99 & 19 & 74 & 1.12 \\
Serruys PW & 73 & 7438 & 101.89 & 28 & 73 & 0.77 \\
Lemos PA & 68 & 1676 & 24.65 & 22 & 40 & 1.10 \\
Lima EG & 67 & 280 & 4.18 & 9 & 16 & 0.75 \\
Favarato D & 64 & 981 & 15.33 & 18 & 30 & 0.82 \\
Rezende PC & 64 & 224 & 3.50 & 9 & 14 & 0.90 \\
Serrano CV & 60 & 730 & 12.17 & 12 & 26 & 0.40 \\
\hline \multicolumn{1}{c}{ TP= "Total Publications", TC= "Total Citations", ACPP= “Average Citations per Paper". }
\end{tabular}

\section{Most Relevant Authors}
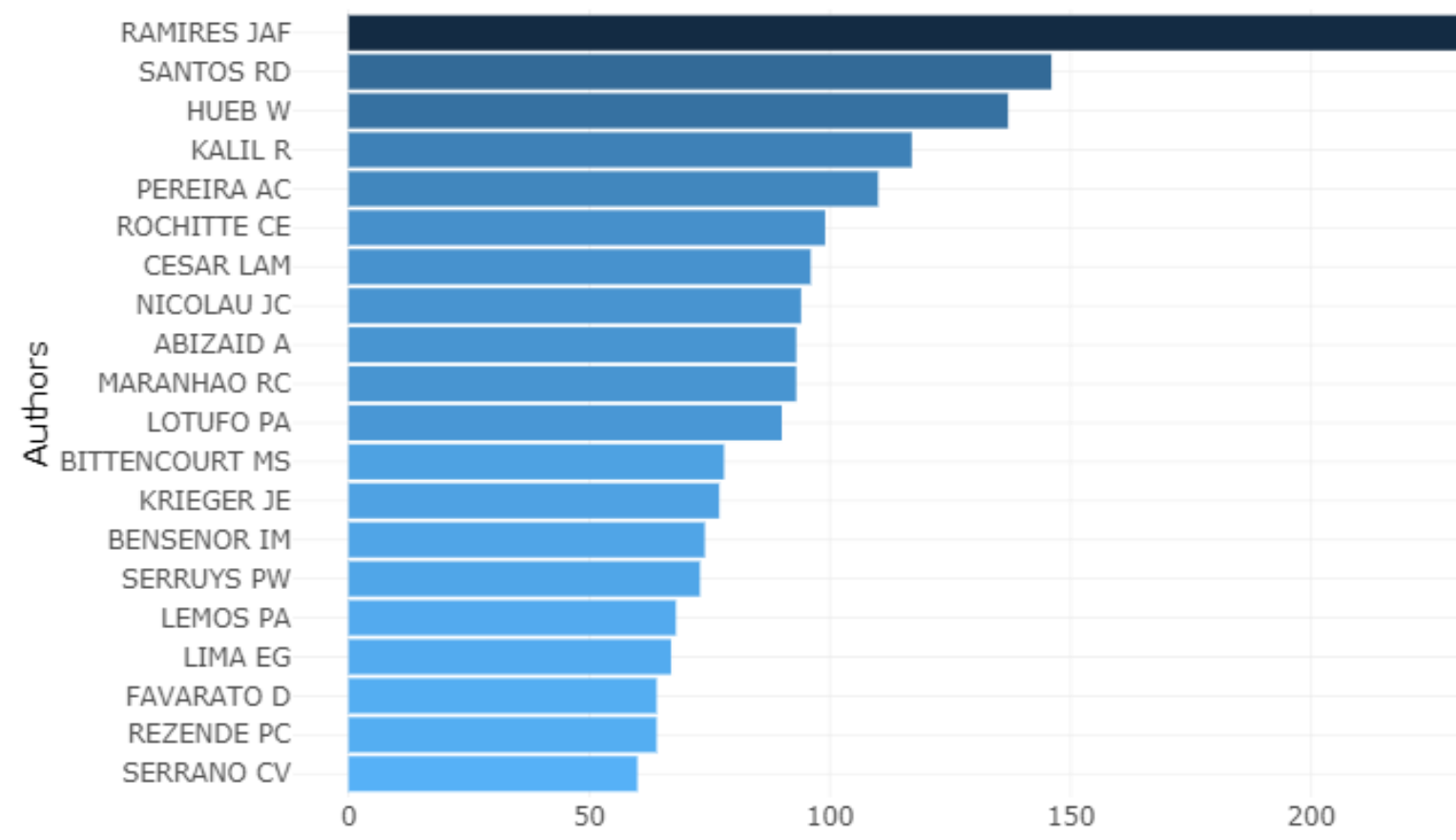

N. of Documents 


\subsection{Authorship Pattern}

Table 5 illustrates the overall and five year wise distribution of authorship trend. It is evident from the Table 5 that only 2.03 per cent publications were single authored publications while rest of 97.97 had two or more authors. The maximum number of publications were more than ten authored publications (16.99 \%) nearly followed by six authored publications (12.78\%), five authored $(11.30 \%)$, seven authored $(10.56 \%)$ and eight authored publications $(9.90 \%)$. Two to nine authored publications accounted for 73.56 per cent while more than 10 authored publications accounted for 16.99 per cent.

Table 5: Authorship Pattern

\begin{tabular}{|c|c|c|c|c|c|c|c|c|}
\hline \multirow{2}{*}{ Author(s) } & \multicolumn{6}{|c|}{ Total Research Output (5 Yearly) } & \multicolumn{2}{|c|}{$\begin{array}{c}\text { Total Research } \\
\text { Output }\end{array}$} \\
\hline & $\begin{array}{l}1990- \\
1994 \\
\end{array}$ & $\begin{array}{l}1995- \\
1999 \\
\end{array}$ & $\begin{array}{r}2000- \\
2004 \\
\end{array}$ & $\begin{array}{l}2005- \\
2009 \\
\end{array}$ & $\begin{array}{l}2010- \\
2014 \\
\end{array}$ & $\begin{array}{l}2015- \\
2019 \\
\end{array}$ & Total & $\%$ \\
\hline Single & 3 & 10 & 9 & 31 & 33 & 40 & 126 & 2.03 \\
\hline Two & 5 & 15 & 34 & 54 & 99 & 116 & 323 & 5.20 \\
\hline Three & 7 & 22 & 34 & 117 & 142 & 132 & 454 & 7.31 \\
\hline Four & 11 & 36 & 55 & 122 & 192 & 171 & 587 & 9.45 \\
\hline Five & 10 & 27 & 72 & 173 & 227 & 193 & 702 & 11.30 \\
\hline Six & 8 & 26 & 81 & 186 & 230 & 263 & 794 & 12.78 \\
\hline Seven & 7 & 36 & 59 & 148 & 219 & 187 & 656 & 10.56 \\
\hline Eight & 5 & 18 & 42 & 138 & 207 & 205 & 615 & 9.90 \\
\hline Nine & 4 & 11 & 27 & 85 & 138 & 173 & 438 & 7.05 \\
\hline Ten & 1 & 9 & 17 & 80 & 173 & 181 & 461 & 7.42 \\
\hline More than 10 & 5 & 13 & 44 & 122 & 283 & 588 & 1055 & 16.99 \\
\hline Total & 66 & 223 & 474 & 1256 & 1943 & 2249 & 6211 & 100.00 \\
\hline$\%$ & 1.06 & 3.59 & 7.63 & 20.22 & 31.28 & 36.21 & 100.00 & \\
\hline
\end{tabular}

\subsection{Top Journals Preferred for Publication}

The total number of 6211 publications on CAD from 1990 to 2019 appeared in 1224 different sources. The top 20 journals preferred for publications on CAD are listed in Table 6 which accounted for 36.32 per cent of total research publications during the period under study. Circulation has published highest (162) publications on CAD followed by Journal of the American College of Cardiology (144). According to the journals preferred for publication output from the table 6 the journal wise distribution of research documents, Circulation has the highest number of research documents 162 with 9316 of total citation score and 42, 96 and $.4 \mathrm{~h}$ index, $\mathrm{g}$ index and $\mathrm{m}$ index respectively and being prominent among the 20 journals and it stood 
in first rank position. Journal of the American College of Cardiology has 144 research documents and it stood in second position with 9113 of total citation score and 39, 95, $1.34 \mathrm{~h}$ index, $g$ index and $\mathrm{m}$ index score were scaled. It is followed by the Lancet with 33 of records and it stood in third rank position along with 19436 of total citation score and 29, 33, and $1.12 \mathrm{~h}, \mathrm{~g}$, and $\mathrm{m}$ index score measured.

Table 6: Top 20 Sources for Publications

\begin{tabular}{clccccc}
\hline S.No. & \multicolumn{1}{c}{ Source of Publication } & NP & TC & $\begin{array}{c}\text { h- } \\
\text { index }\end{array}$ & $\begin{array}{c}\text { g- } \\
\text { index }\end{array}$ & $\begin{array}{c}\text { m- } \\
\text { index }\end{array}$ \\
\hline 1 & Circulation & 162 & 9316 & 42 & 96 & 1.4 \\
2 & Journal of the American College of Cardiology & 144 & 9113 & 39 & 95 & 1.34 \\
3 & Lancet & 33 & 19436 & 29 & 33 & 1.12 \\
4 & Stroke & 80 & 2040 & 28 & 45 & 1.04 \\
5 & European Heart Journal & 156 & 4477 & 26 & 66 & 0.96 \\
6 & Atherosclerosis & 106 & 2108 & 25 & 42 & 0.96 \\
7 & Arquivos Brasileiros De Cardiologia & 456 & 3088 & 22 & 35 & 1.57 \\
8 & American Journal of Cardiology & 60 & 1455 & 22 & 37 & 0.76 \\
9 & International Journal of Cardiology & 111 & 1503 & 21 & 32 & 0.72 \\
10 & American Heart Journal & 46 & 1289 & 20 & 35 & 0.65 \\
11 & Brazilian Journal of Medical and Biological Research & 133 & 1485 & 19 & 29 & 0.63 \\
12 & Arquivos De Neuro-Psiquiatria & 240 & 1477 & 18 & 23 & 0.69 \\
13 & Clinics & 84 & 1038 & 18 & 27 & 1.29 \\
14 & Plos One & 62 & 841 & 18 & 26 & 1.5 \\
15 & Revista Brasileira De Cirurgia Cardiovascular & 113 & 843 & 16 & 19 & 1.23 \\
16 & Transplantation Proceedings & 59 & 440 & 13 & 16 & 0.72 \\
17 & Catheterization and Cardiovascular Interventions & 46 & 875 & 12 & 29 & 0.7 \\
18 & Acta Cirurgica Brasileira & 77 & 428 & 11 & 14 & 0.79 \\
19 & Journal of Stroke \& Cerebrovascular Diseases & 40 & 204 & 9 & 12 & 0.9 \\
20 & Revista Da Associacao Medica Brasileira & 48 & 250 & 8 & 13 & 0.57 \\
\cline { 2 - 7 } & $\quad$ NP= "Number of Publications", TC= “Total Citations" & & &
\end{tabular}




\section{Source Impact}

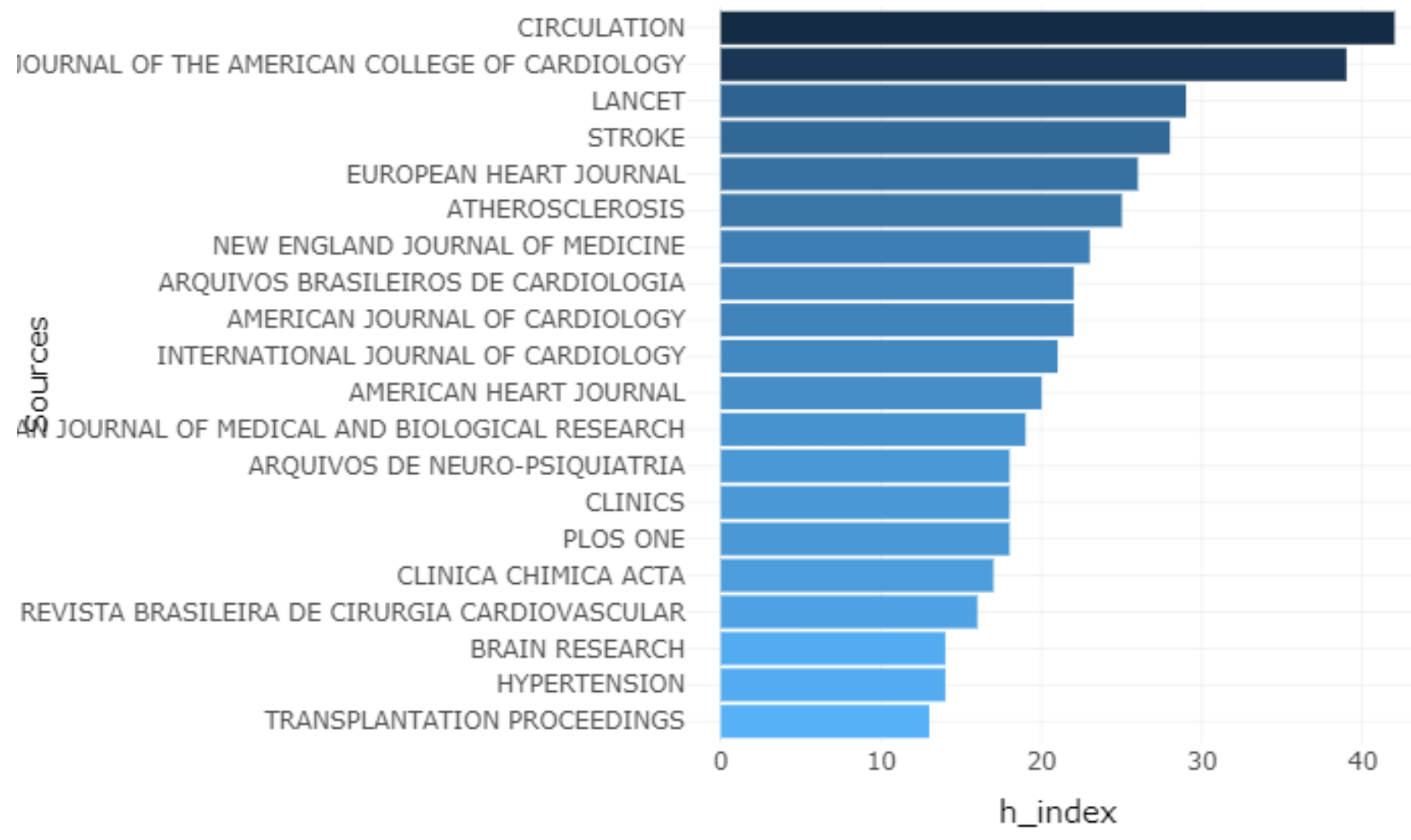

\section{Conclusion}

The study explores the 30 years research output on CAD in Brazil level. It was found that a total number of 6211 papers on CAD were published during 1990-2019 which received 160218 citations with ACPP of 25.80. Growth rate was highest (70.40\%) in the block year 1995-1999. ACCP of Harvard University was highest with 195.74 average citations per paper. Nearly 36.32 per cent of research on CAD was published in 20 journals among which Circulation produced highest research output on CAD. Ramires JAF and Santos RD were the front runners in terms of number of publications but in terms of citations and ACPP Lotufo PA and Serruys PW remained at top. Only 2.03 per cent publications were single authored publications while rest of 97.97 had two or more authors. Among all type of publications, articles and reviews received more citations. The study depicts that research work on CAD was very less in earlier years or decades but increased during the later decades. Major research output was produced near 21 st century especially during the last decade. 


\section{References}

Ahmad, M., \& Batcha, M. S. (2019). Mapping of Publications Productivity on Journal of Documentation 1989-2018: A Study Based on Clarivate Analytics - Web of Science Database. Library Philosophy and Practice (e-Journal), 2213-2226.

Ahmad, M., \& Batcha, M. S. (2019). Scholarly Communications of Bharathiar University on Web of Science in Global Perspective: A Scientometric Assessment. Research Journal of Library and Information Science, 3(3), 22-29.

Ahmad, M., \& Batcha, M. S. (2020). Coronary Artery Disease Research in India: A Scientometric Assessment of Publication during 1990-2019. Library Philosophy and Practice (e-Journal). Retrieved from https://digitalcommons.unl.edu/libphilprac/4178

Ahmad, M., \& Batcha, M. S. (2020). Examining the Scientific Productivity of Authors in Dyslexia Research: A Study Using Lotka's Law. Library Philosophy and Practice (eJournal). Retrieved from https://digitalcommons.unl.edu/libphilprac/4198

Ahmad, M., \& Batcha, M. S. (2020). Identifying and Mapping the Global Research Output on Coronavirus Disease: A Scientometric Study. Library Philosophy and Practice (e-Journal). Retrieved from https://digitalcommons.unl.edu/libphilprac/4125

Ahmad, M., Batcha, M. S., \& Dar, Y. R. (2020). Research Productivity of the Brain and Language Journal from 1999 -2018 : A Scientometric Analysis. Journal of Advancements in Library Sciences, 7(1), 91-99.

Ahmad, M., Batcha, M. S., \& Jahina, S. R. (2019). Testing Lotka's Law and Pattern of Author Productivity in the Scholarly Publications of Artificial Intelligence. Library Philosophy and Practice (e-Journal) (Vol. 2019). University of Idaho Library. Retrieved from https://digitalcommons.unl.edu/libphilprac

Ahmad, M., Batcha, M. S., Rashid, W., \& Hafiz, O. (2018). Calculating Web Impact Factor for University Websites of Jammu and Kashmir: A Study. International Journal of Science, Technology and Management (IJSTM), 7(05), 17-27.

Ahmad, M., Batcha, M. S., Wani, B. A., Khan, M. I., \& Jahina, S. R. (2018). Research Output of 
Webology Journal ( 2013-2017 ): A Scientometric Analysis. International Journal of Movement Education and Social Science, 7(3), 46-58.

Batcha, M. S., \& Ahmad, M. (2017). Publication Trend in an Indian Journal and a Pakistan Journal: A Comparative Analysis using Scientometric Approach. Journal of Advances in Library and Information Science, 6(4), 442-449.

Batcha, M. S., Dar, Y. R., \& Ahmad, M. (2019). Impact and Relevance of Cognition Journal in the Field of Cognitive Science: An Evaluation. Research Journal of Library and Information Science, 3(4), 21-28.

Batcha, M. S., Dar, Y. R., \& Ahmad, M. (2020). Global Research Trends in the Modern Language Journal from 1999 to 2018: A Data-Driven Analysis. Research Journal of Library and Information Science, 4(2), 1-8.

Batcha, M. S., Jahina, S. R., \& Ahmad, M. (2018). Publication Trend in DESIDOC Journal of Library and Information Technology during 2013-2017: A Scientometric Approach. International Journal of Research in Engineering, IT and Social Sciences, 8(04), 76-82.

Braunwald, E., \& Bonow, R. O. (2012). Braunwald's heart disease: a textbook of cardiovascular medicine. Philadelphia: Saunders.

Egghe, L. (2006). Theory and practise of the g-index. Scientometrics, 69(1), 131-152. https://doi.org/10.1007/s11192-006-0144-7

Epstein, F. H., Blackburn, H., \& Gutzwiller, F. (1996). Cardiovascular disease epidemiology: A journey from the past into the future. Circulation, 93(9), 1755-1764. https://doi.org/10.1161/01.CIR.93.9.1755

Go, A. S., Mozaffarian, D., Roger, V. L., Benjamin, E. J., Berry, J. D., Blaha, M. J., .. Turner, M. B. (2014). Executive summary: heart disease and stroke statistics--2014 update: a report from the American Heart Association. Circulation, 129(3), 399-410. https://doi.org/10.1161/01.cir.0000442015.53336.12

Hirsch, J. E. (2010). An index to quantify an individual's scientific research output that takes into account the effect of multiple coauthorship. Scientometrics, 85(3), 741-754. 
https://doi.org/10.1007/s11192-010-0193-9

Jahina, S. R., Batcha, M. S., \& Ahmad, M. (2020). Lotka's Law and Pattern of Author Productivity in the Field of Brain Concussion Research: A Scientometric Analysis. Library Philosophy and Practice (e-Journal). Retrieved from https://digitalcommons.unl.edu/libphilprac/4126

Keys, A. (1980). Seven countries. A multivariate analysis of death and coronary heart disease. London: Harvard University Press.

Keys, A., Taylor, H. L., Blackburn, H., Brozek, J., Anderson, J. T., \& Simson, E. (1963). Coronary Heart Disease Among Minnesota Business and Professional Men Followed Fifteen Years. Circulation, 28(3), 381-395. https://doi.org/10.1161/01.CIR.28.3.381

Khera, A. V, \& Kathiresan, S. (2017). Genetics of coronary artery disease: discovery, biology and clinical translation. Nature Reviews. Genetics, 18(6), 331-344. https://doi.org/10.1038/nrg.2016.160

Umar, A. A., Ahmad, M., \& Batcha, M. S. (2020). Library and Culture: A Scientometric Analysis and Visualization of Research Trends. Journal of Cultural and Social Anthropology, 2(2), 1-08.

Wong, N. D. (2014). Epidemiological studies of CHD and the evolution of preventive cardiology. Nature Reviews. Cardiology, 11(5), 276-289. https://doi.org/10.1038/nrcardio.2014.26 